\title{
Techno-economic assessment of energy storage systems for enabling projected increase of renewables onto electrical power grids.
}

\author{
GAZEY, R., ALI, D. and AKLIL, D.
}

This paper is a postprint of a paper submitted to and accepted for publication in Proceedings of IET (Institution of Engineering and Technology) Renewable power generation conference 2011 (RPG 2011), 6-8 September 2011, Edinburgh, UK and is subject to Institution of Engineering and Technology Copyright. The copy of record is available at IET Digital Library. 


\title{
TECHNO-ECONOMIC ASSESSMENT OF ENERGY STORAGE SYSTEMS FOR ENABLING PROJECTED INCREASE OF RENEWABLES ONTO ELECTRICAL POWER GRIDS
}

\author{
R. Gazey*, Dr. D. Ali*, Dr. D. Aklil ${ }^{\dagger}$ \\ ${ }^{\star}$ Robert Gordon University \\ 'Pure Energy Centre
}

Keywords: Energy Storage, Fuel-Cell, Hydrogen, Economics

\begin{abstract}
Hydrogen is seen by many industry leaders as an energy vector that has the potential to provide essential energy stores required to facilitate the wide spread connection of renewable energy inputs. The techno economic assessment of using hydrogen as an energy storage mechanism, where water $(\mathrm{H} 2 \mathrm{O})$ is split into $\mathrm{H} 2$ and Oxygen $(\mathrm{O} 2)$ when excess renewable energy is available through the use of electrolysis will be examined. $\mathrm{H} 2$ will be stored and $\mathrm{O} 2$ vented. Fuel Cells (FC), Internal Combustion Engines (ICE) or gas turbines would then be used to convert stored $\mathrm{H} 2$ to generate and supply electrical infrastructure with electrical power when demand exceeds renewable supply. Presented in this paper are the findings of a techno economic assessment of existing energy storage systems in comparison to Hydrogen (H2) energy storage technologies.
\end{abstract}

\section{Introduction}

Economical and environmental pressures coupled with recent significant increases of fossil fuel costs have led to the rapid expansion of electricity generation from Renewable Energy Sources (RES). It has been indicated that as much as $46 \%$ of global electricity could be delivered from RES by 2050 [12]. In addition BPs 2011 energy forecast predict Fossil fuel energy source growth to fall from $83 \%$ to $64 \%$ of market share in favour of renewable energy sources in their 2030 energy outlook [26].

Electrical power transmission and distribution grids used around the world today must now become much more robust as they integrate increasingly larger quantities of fluctuating and intermittent renewable power sources and a growing number of small, decentralised power producers. Electrical networks must also have the ability to store excess power fed into the grid from fluctuating and intermittent power sources. Energy Storage Systems (ESS) are a proposed solution to help facilitate the connection of the predicted growth in grid connected RES. It is crucial to the wide spread adoption of ESS to be able to assess their technical abilities and economic impact when proposing their integration into existing electrical infrastructure.

All electrical ESS have varying degrees of inefficiency as part of the energy supplied into an energy storage systems cannot later be discharged due to system efficiency losses. Typical efficiency factors range from $45 \%$ to $80 \%$ depending on technology and storage application, and is the main weakness of all existing electrical storage technologies [25]. Efficiency losses are also a significant contributing factor to the existing perception of an unfavourable business case for their use. In common with conventional power stations, the economic case for energy storage systems is also affected by many other factors such as the cost of charging electrical energy, capital costs, operation and maintenance costs and discharge/recharge) cycle life [21]. In addition the utilisation of an energy storage facility is a complex interaction of electrical transmission and distribution constraints, renewable resource and demand/supply issues.

Many technologies for the large scale storage of electrical energy are still relatively technologically immature [2]. One notable exception to this is pumped hydroelectric energy storage. The inclusion of ESS brings with it additional costs over and above the initial costs of energy generation. ESS will also incur additional capital (Capex) and operational (Opex) costs associated with the energy conversion loss efficiencies. There is also limited large scale operational and testing experience available. However, despite these potential drawbacks, ESS will still provide a vital role in enabling the projected increases in renewable and sustainable energy technologies onto electrical transmission and distribution networks. In order to allow applying ESS in the most appropriate manor a techno-economic assessment of ESS is presented here with a focus on the hydrogen energy storage technology abilities, such as the value of the sale of $\mathrm{O} 2$ and $\mathrm{H} 2$ gases in addition to the raw energy value.

\section{ESS Characteristics}


A number of Energy Storage Systems have been considered for comparison with $\mathrm{H} 2$ technology deployed as an ESS. To enable comparison a number of key characteristics are summarised below. A 'traditional' energy storage system for electrical energy can be considered as shown in figure 1 below. Where electrical input energy is converted and stored within a medium until released as electrical energy when required.

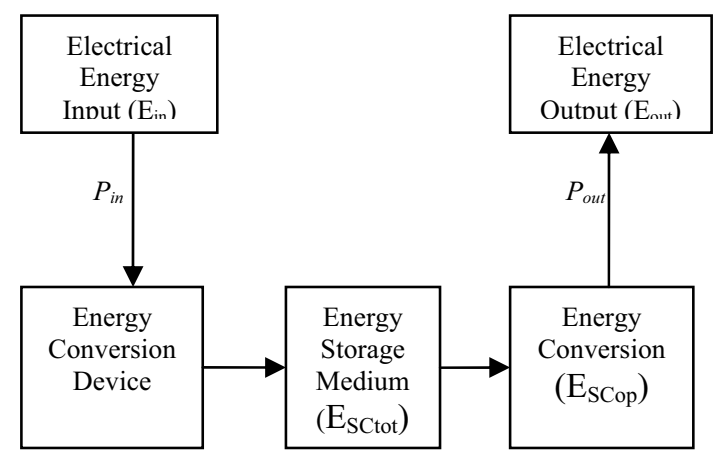

Figure 1: simplified overview of electrical energy storage.

\subsection{Depth of Discharge (DoD)}

The DoD defines the ability of an ESS to release its stored energy. Typically it is not possible to release $100 \%$ of the stored energy within an ESS and much lower value is achievable in order to sustain the lifetime of electrochemical ESS [11].

\subsection{Duration - storage capacity ( $\mathrm{kWh})$}

Storage capacity $\left(\mathrm{E}_{\mathrm{SCtot}}\right)$ is defined as the total energy storage within an ESS or $100 \%$ of its capacity. This is always greater than the energy that can be released from an ESS in operation $\left(\mathrm{E}_{\mathrm{SCop}}\right)$ due to a variety of factors including DoD, efficiency and charge/discharge rates [18]. Therefore:

$$
\mathrm{E}_{\mathrm{SCtot}}>\mathrm{E}_{\mathrm{SCop}}
$$

\subsection{Charge/Discharge rates}

The charge $\left(\mathrm{P}_{\text {in }}\right)$ and discharge $\left(\mathrm{P}_{\text {out }}\right)$ rates define the ability for an ESS to both absorb and release their stored energy. Traditional battery storage system charge/discharge rates are a function of their overall capacity [7].

\subsection{Turn-Around Efficiency}

The ESS turn around efficiency is the ratio between input energy and output energy. ESS ( $\eta$ ) can be represented as shown in equation (2).

$$
\eta=E_{\text {in }} / E_{\text {out }}
$$

Where $E_{\text {in }}$ is the input energy and $E_{\text {out }}$ is the output energy recoverable from the ESS [22].

\subsection{Cost indicators}

In the UK Renewable Obligation Certificate (ROC) and climate change Levy Exemption Certificate (LEC) income for wind farms over $5 \mathrm{MW}$ in size typically receive and income at around $£ 55$ per MWh [15].

The practice of constraining generation off grid has not resulted in any losses to renewable energy generators. However the recent increase in renewable energy generation onto electrical infrastructure has resulted in a loss of traded energy as generation is constrained 'off grid' to maintain electrical network stability [14]. The implication for renewable energy generators is that if no mitigating measures are taken then the value of their energy will fall.

It is important to note that the value of energy constrained off grid is not lost to the generator. Compensation payments are made to the generator whose energy is constrained. However the value of these constraint payments is considered to be very high for renewable generation. As widely publicised and summarised in the Renewable Energy Foundation, "Scottish wind power constraint payments update" on the $28^{\text {th }}$ June 2011, average constraint payments were £215 per MWh between the $30^{\text {th }}$ May 2010 and 16 June 2011. During the same time period $23747 \mathrm{MWh}$ of renewable energy were constrained off grid.

One of the main cost indicators for defining an 'on grid' energy storage system are the difference between the cost of input energy $\left(\mathrm{EC}_{\mathrm{in}}\right)$ and output energy $\left(\mathrm{EC}_{\text {out }}\right)$ value, along with efficiency losses $\eta$ [17]. Additionally the value of constraint payments described could also be considered as potential cost savings for network operators. Also there are additional cost indicators for Hydrogen energy storage that may have the potential to attract revenue. These are the resale/wholesale value Hydrogen Oxygen as a by-product.

The wholesale cost of Hydrogen can be represented as $\mathrm{H} 2_{\mathrm{c}}$ and $\mathrm{Oxygen}$ as $\mathrm{O} 2_{\mathrm{c}}$.

\section{Summary of ESS}

A number of different ESS systems have been considered for comparison within this paper, these are described in brief below.

\subsection{Battery Energy Storage (BES)}

One of the most established methods for storing electrical energy is in the form of chemical energy in batteries. Batteries consist of single or multiple electrochemical cells each constituted from an electrolyte material with an attached positive and negative electrode. Discharging a battery causes an electrochemical reaction to occur at the electrodes generating a flow of electric current through an external circuit. These reactions are reversible and allow the battery to 
be recharged by applying an external power source to the electrodes. Battery systems can be divided into mature technology such as lead acid and newer designs that are in different stages of development. In recent years the development of battery technology has been driven by the demands of consumer electronics, portable and transport applications. However, there has been increasing interest in the use of large scale batteries for use with renewable energy systems and electrical network support. Battery technologies that would seem to be most suited to use with renewable energy systems include lead acid (pB), nickel cadmium $(\mathrm{NiCd})$, sodium sulphur $(\mathrm{NaS})$ and sodium nickel chloride $(\mathrm{NaNiCl})$.

\subsection{Pumped Hydro Storage (PHS)}

Pumped Hydro storage systems utilise off peak electrical power to pump water into a reservoir located at an elevated position such as a hill or mountain. Energy is thereby stored as potential energy in the form of water at height. During times of peak demand water is released from the high level reservoir and fed through a hydro turbine which generates electrical energy for end use.

\subsection{Flywheel Energy Storage (FES)}

Flywheel based ESS includes a rapidly rotating mass attached to a drive shaft and housed within a highly robust enclosure. Magnetic forces are used to significantly reduce frictional losses and operational wear. The drive shaft is connected to an electrical motor/generator. The electrical energy is stored by the motor/generator as kinetic energy within the rotating mass. Stored energy is then released as electricity via the motor/generator.

\subsection{Compressed Air Energy Storage (CAES)}

CAES is an energy storage technology that is used to improve the efficiency of a combined cycle gas turbine (CCGT) power stations. CAES consumes off-peak electricity to compress air that is then stored in an airtight reservoir or underground geological formation. The stored energy is recovered when the compressed air is released from the reservoir through a gas-fired combustion turbine. The compressed air replaces the gas turbines compressor stage enabling a reduction of up to $60 \%$ in natural gas consumption. The use of the compressed air in a purely air driven turbine is not presently possible with existing state of the art designs as the expanding air through an air only turbine results in the turbine freezing up. This caused by the cooling effect caused by expanding compressed air back to ambient pressures. However, unlike other storage technologies, CAES still ultimately requires the use of natural gas to release stored energy resulting in additional $\mathrm{CO} 2$ production from this form of storage technology. It has been suggested that in principle, CAES could be combined with Carbon Capture and Storage (CCS) [3].

\subsection{Hydrogen \& Fuel Cell Energy Storage Technologies}

The essential elements of an energy storage system based on hydrogen technology are shown in figure 1 below.

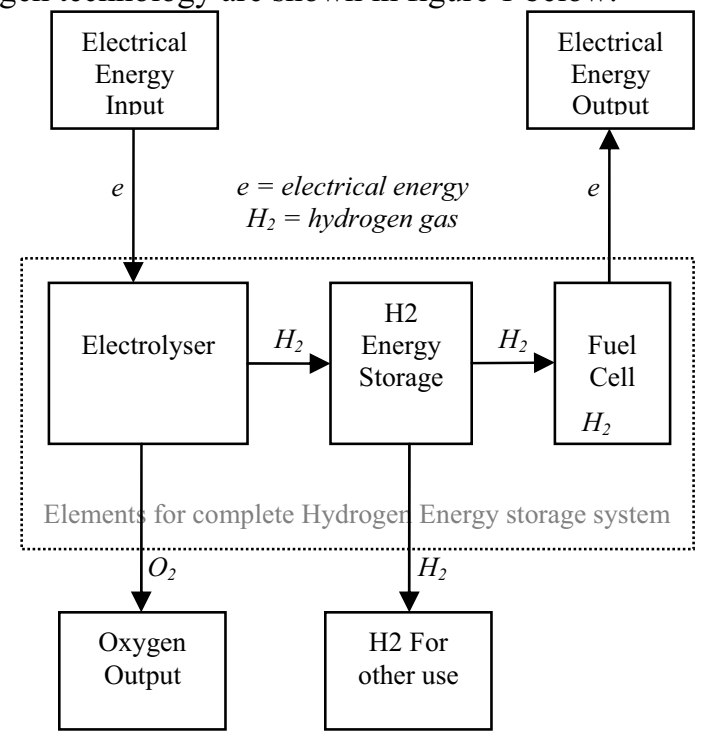

Figure 2: Basic elements of a hydrogen energy system.

The electrolyser is used to convert electrical energy from an energy source (typically renewable) into Hydrogen for storage. The Hydrogen storage system is used to store the Hydrogen gas. The Hydrogen storage method can take a number of forms (pressurised gas, Metal Hydride, liquid Dewar tank). Finally a hydrogen energy conversion system recovers the stored chemical energy in the hydrogen and converts it back into electrical energy for use. The hydrogen energy conversion system commonly cited for use in energy systems is a fuel cell. A fuel cell is commonly cited for use as its conversion efficiency is a lot higher than combustion engine technology [6]. Typical average electrical conversion efficiencies recorded on the fuel cell used within the PURE Project energy system [23] and the Hydrogen Office range between $40 \%$ - $50 \%$ compared with a maximum of $37 \%$ for a small combustion engine [24].

Shown in table one below are a summary of technology costs described from literature.

\begin{tabular}{|l|l|l|l|l|}
\hline $\begin{array}{l}\text { Technology } \\
{[1,8,4,16]}\end{array}$ & $\boldsymbol{\epsilon} / \mathbf{k W h}$ & $\boldsymbol{\epsilon} / \mathbf{k W}$ & $\begin{array}{l}\text { Life time } \\
\text { (years) }\end{array}$ & $\begin{array}{l}\text { Eff } \\
\mathbf{( \% )}\end{array}$ \\
\hline $\begin{array}{l}\text { Pumped } \\
\text { hydro }\end{array}$ & $10-20$ & $500-1500$ & $40-80$ & $65-80$ \\
\hline Fuel Cell & $2-15$ & $300-1000$ & $10-20$ & $35-45$ \\
\hline Battery & $210-250$ & $125-150$ & $10-15$ & $75-85$ \\
\hline Flywheel & $150-200$ & $200-250$ & 20 & 90 \\
\hline CAES & $3-5$ & $300-600$ & $20-40$ & $80-85$ \\
\hline
\end{tabular}

Table 1: summary of energy storage costs from literature.

\section{Energy storage efficiency}

Energy storage efficiency can be viewed in a number of ways. The most common method of measuring energy storage system efficiency is by comparing the input energy used to fill the energy storage with the recoverable output energy. It is also important however to consider the economic efficiency of an ESS. Hydrogen as a potential energy storage 
mechanism has the ability not only to store electrical energy for re-use, but also to offer the potential to sell both hydrogen and oxygen gasses as commodities.

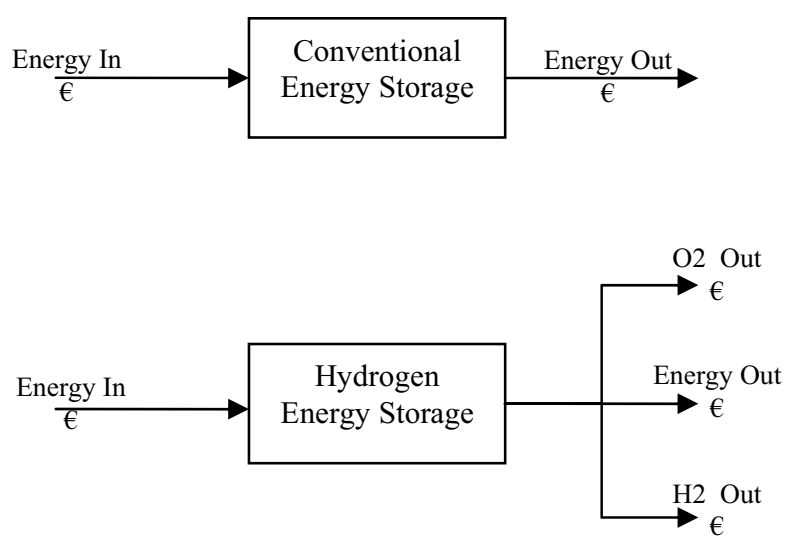

Figure 3: Diagram of additional revenue sources.

Shown in figure 3, is a diagram that depicts the potential for hydrogen energy storage systems to realise three possible revenue streams. This is in contrast to conventional energy storage systems where there is only one possible revenue stream for energy. Typically conventional network connected energy storage systems allow for energy to be stored and realised in the form of only electrical energy. Hydrogen has the additional ability to provide opportunity to generate revenue from two additional outputs. These are the sale of hydrogen gas, or Oxygen gas as well as the potential to release the energy as electrical energy. In the context of this research it is these additional revenue streams that have the potential for hydrogen energy storage systems to offer greater financial efficiency. Whilst not the main focus of this research it is worth mentioning that the 3:1 increase in revenue options also opens up potential for possible downstream applications. Literature shows potential for a great deal of flexibility for hydrogen usage where conventional energy storage systems do-not. Examples of such opportunities include fertiliser production, electrical generation and high and low grade heat applications [13].

\section{Cost of electrical generation}

Energy Generation costs is typically represented in the form of a levelised cost. The levelised cost of electricity generation is the discounted lifetime cost [20] of owning and operating a generation facility. Levelised cost is often described as a measure of the overall competitiveness of different generation technologies and represents the present value of the total cost of constructing and operating a power generating station over an assumed lifetime. The levelised cost of energy generation (LGC) can be shown by the Net Present Value (NPV) of electrical generation divided by the NPV of the energy generation station as shown in equation 3 [19].

$$
L G C=\frac{\sum_{t=1}^{n} \frac{I G C_{t}+G O M_{t}+F_{t}}{(1+r)^{t}}}{\sum_{t=1}^{n} \frac{E_{t}}{(1+r)^{t}}}
$$

Where: $\mathrm{IGC}_{\mathrm{t}}=$ Invested Generation capital in year $(\mathrm{t})$

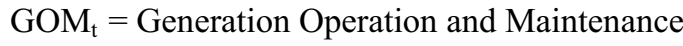
costs in year $(\mathrm{t})$

$\mathrm{F}_{\mathrm{t}} \quad=$ Fuel Costs in year $(\mathrm{t})$

$\mathrm{r} \quad=$ Annual discount rate (typically 10\%) [10]

$\mathrm{E}_{\mathrm{t}} \quad=$ Value (cost) of generated energy in year $(\mathrm{t})$

$\mathrm{n} \quad=$ Total number of years assumed plant life

The levelised cost of generation as expressed in equation 3 is applied to the cost analysis model used in assessing the economics of hydrogen as an energy storage vector. The levelised cost of generation can be considered the input energy cost applied to the energy storage.

\section{Cost of Energy Storage}

Following a similar approach to energy generation the costs of energy storage have been considered using a levelised cost approach. Equation 3 is expanded to consider the cost of input energy. Equation 4 below expresses the Levelised Storage Costs (LSC):

$$
L S C=\frac{\sum_{t=1}^{n} \frac{I S C_{t}+S O M_{t}+E C_{t}}{(1+r)^{t}}}{\sum_{t=1}^{n} \frac{E O_{t}}{(1+r)^{t}}}
$$

Where: $\mathrm{ISC}_{\mathrm{t}}=$ Invested Storage Capital in year ( $\mathrm{t}$ )

$\mathrm{SOM}_{\mathrm{t}}=$ Storage Operation and Maintenance costs in year $(\mathrm{t})$

$\mathrm{EC}_{\mathrm{t}} \quad=$ input energy cost $(\mathrm{t})$

$\mathrm{r} \quad=$ Annual discount rate (typically 10\%) [10]

$\mathrm{EO}_{\mathrm{t}}=$ Value of released energy in year $(\mathrm{t})$

Energy storage within the context of this study relates to energy stored that would otherwise be lost due to network constraint issues. In this case the Energy from a RES can be considered to have limited value. In order for the ESS to achieve a breakeven value for units of 'rejected' energy onto the transmission and distribution system an energy storage system would therefore have to accept energy at a price less than the LGC as expressed in equation 3 above. In this case $\mathrm{EC}_{\mathrm{t}}$ can be expressed as shown in equation 5 :

$$
\mathrm{EC}_{\mathrm{t}}<\mathrm{LGC}
$$

As previously discussed above, energy storage developed around Hydrogen technology will have additional revenue potential. This can be realised in the sale of both hydrogen and oxygen gasses as a commodity. Equation 4 can therefore be expanded upon to include $\mathrm{H} 2_{t}$ and $\mathrm{O} 2_{t}$, where the $\mathrm{H} 2_{\mathrm{t}}$ and $\mathrm{O} 2_{\mathrm{t}}$ are the realisable value of both hydrogen and oxygen in 
year $(t)$. Therefore the levelised cost of energy storage can be expressed as shown in equation 6 .

$$
L S C=\frac{\sum_{t=1}^{n} \frac{I S C_{t}+S O M_{t}+E C_{t}}{(1+r)^{t}}}{\sum_{t=1}^{n} \frac{E O_{t}+H 2_{t}+O 2_{t}}{(1+r)^{t}}}
$$

Where: $\mathrm{ISC}_{\mathrm{t}}=$ Invested Storage Capital in year $(\mathrm{t})$

$\mathrm{SOM}_{\mathrm{t}}=$ Storage Operation and Maintenance costs in year $(\mathrm{t})$

$\mathrm{EC}_{\mathrm{t}}=$ input energy cost $(\mathrm{t})$

$\mathrm{r} \quad=$ Annual discount rate (typically 10\%) [10]

$\mathrm{EO}_{\mathrm{t}} \quad=$ Value of sold energy in year $(\mathrm{t})$

$\mathrm{H} 2_{\mathrm{t}} \quad=$ Value of sold hydrogen gas year $(\mathrm{t})$

$\mathrm{O} 2_{\mathrm{t}}=$ Value of sold Oxygen gas in year $(\mathrm{t})$

\section{Analysis}

Within this study several configurations for hydrogen storage systems have been compared. Levelised cost (or total annualized cost) of the initial capital investment, including operating costs over the lifespan of a hydrogen facility divided by the total yearly output from the storage system have been calculated.

Analysis evaluated scenarios for producing hydrogen and oxygen gasses utilising surplus or 'constrained' renewable energy as described in section 2.5 above. The analysis assumed the following scenarios for operating a hydrogen energy storage system as follows:

Scenario A. No FC - (no energy sale), 100\% 02 \& H2 gas sold

Scenario B. $\quad 100 \%$ energy sale - 3MW FC, $100 \% 02$ sold, no h2 sale

Scenario C. $\quad 50 \% \mathrm{O} 2$ \& $\mathrm{H} 2$ gas sold, $50 \% \mathrm{H} 2$ sold as Energy through a $3 \mathrm{MW} \mathrm{FC}$

Scenario D. No FC - (no energy sale), No 02 Sold, $100 \% \mathrm{H} 2$ sold

Scenario E. $\quad 100 \%$ Energy sold (3MW FC), no O2 nor H2 sold

In each scenario, hydrogen storage capacity has been defined as $5 \mathrm{MWh}$ pressurised gas storage.

Market data provided by the Pure Energy Centre shows hydrogen capital costs as in the table below:

\begin{tabular}{|l|r|l|}
\hline Electrolysis & 2500 & $€ / \mathrm{kW}$ \\
\hline Pressurised Storage & 77 & $€ / \mathrm{kWh}(\mathrm{HHV})$ \\
\hline Fuel Cell & 4000 & $€ / \mathrm{kW}$ \\
\hline
\end{tabular}

Table 2: Hydrogen technology market data [5].

The levelised cost per unit output for the 5 scenarios described above is shown in figure 4. These results have been calculated using the formulas developed as part of this research that is described in detail in the previous sections. As can be seen the lowest output unit cost can be realised in scenario A. Additionally a favourable result is also seen in Scenario C. The highest unit output cost is seen in scenario E.

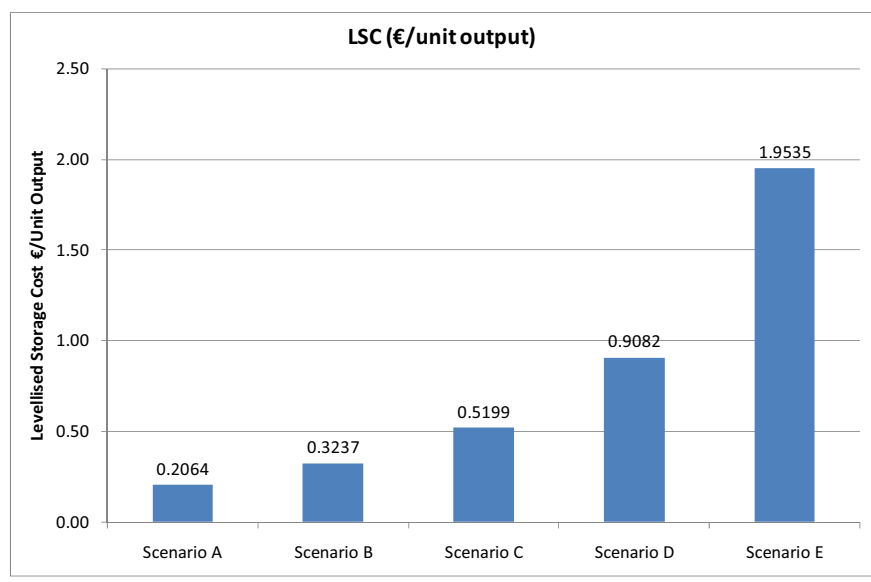

Figure 4: levelised output costs for H2 energy storage system.

Research conducted by NREL [9] has shown energy storage systems to exhibit levelised energy costs as shown in table 3. For comparison these levelised energy storage costs are also shown in figure 5 along with the hydrogen energy storage values described.

\begin{tabular}{|l|rc|}
\hline NiCd Battery & $€$ & 0.58 \\
\hline NaS Battery & $€$ & 0.17 \\
\hline Vanadium Redox battery & $€$ & 0.19 \\
\hline Pumped hydro & $€$ & 0.09 \\
\hline CASE & $€$ & 0.07 \\
\hline
\end{tabular}

Table 3: levelised costs of other energy storage technology.

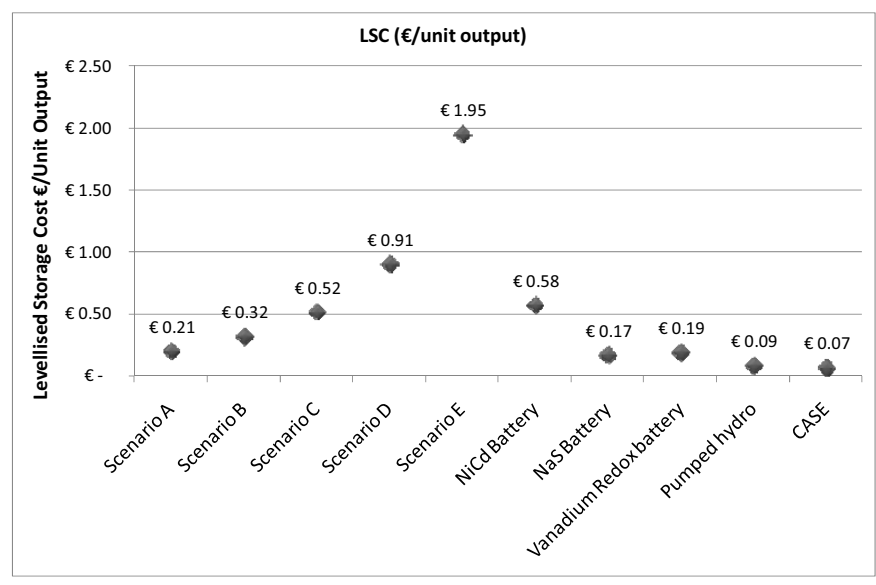

Figure 5: levelised cost comparisons.

\section{Conclusion}

A techno-economic assessment of energy storage systems for enabling projected increase of renewables onto electrical power grids has been shown. It has been shown that hydrogen for use as an energy storage mechanism has the 
most potential where oxygen is also sold. Hydrogen has the greatest potential and financial benefit to enable the projected increase in renewable generation onto the electrical network as it allows surplus renewable energy alternative economic pathways to be utilised. This is due to hydrogen energy storage systems ability to utilise hydrogen directly as an energy carrier and take advantage of its inherent flexibility of end use. i.e. an H2 ESS is not only limited to electrical energy storage for electrical energy production.

\section{Further work}

Additional work is required to also consider the overall lifecycle costs including the costs of decommissioning. In addition the potential cost savings of reduced 'spinning reserve' should also be considered in future analysis. There is also a need to examine the socioeconomic potential for hydrogen as an ESS.

\section{Acknowledgements}

The authors would like to thank those who have made the work described within this paper possible. The research is sponsored by the Environmental Technology Partnership (ETP) the Pure Energy Centre and the Robert Gordon University through IDEAS.

\section{References}

[1] A. Marshall, "Electricity Storage Struggles to add up", Ends Report 435, April 2011.

[2] C.Pieper \& H.Rubel, "Electricity Storage - Making LargeScale Adoption of Wind \& Solar Energies A Reality", The Boston Consulting Group, March 2010.

[3] Chen, H., Ngoc Cong, N., Yang, W., Tan, C.,Li, Y. and Ding, Y. (2009) Progress in electrical energy storage systems: A critical review. Progress in Natural Science 19, 291-312.

[4] D. Connolly, "A Review of Energy Storage Technologies For the integration of fluctuating renewable energy", University of Limerick, August 2009

[5] Dr.D.Aklil, "market analysis data", internal documentation, Pure Energy Centre, 2010.

[6] Dr. D.Ali, Dr, D.Aklil, "Modeling a Proton Exchange Membrane (PEM) Fuel Cell System as a hybrid Power Supply for standalone applications" APPEEC, March 2011.

[7] D.B.Nelson, M.H. Nehir, C.Wang, "Unit sizing and cost analysis of stand-alone hybrid wind/PV/fuel cell power generation systems", Renewable Energy 31 (2006).

[8] D.Lumb, "Energy Storage \& Renewables, is it an uphill struggle?”, Edison Mission Energy.

[9] Darlene Steward et al, "Cost Analysis Highlights Hydrogen's Potential for Electrical Energy Storage", NREL, Hydrogen \& Fuel Cell Technical Highlights, 2010.
[10] Department of Energy and Climate Change (DECC), "Energy price statistics", http://www.decc.gov.uk/en/ content/cms/statistics/energy_stats/prices/prices.aspx.

[11] H. Ibrahim, A.Ilinca, J.Perron, "Energy storage systems characteristics and comparisons", Renewable Energy Reviews 12 (2008).

[12] International Energy Agency, "Energy Technology Perspectives 2008 - Scenarios and Perspectives to 2050", (Paris, 2008), 643 pp. (2010 edition now in print).

[13] J.C. Ganley, "Solid State and Electrolytic Ammonia Production", Howard University, Department of Chemical Engineering.

[14] Dr. J.Constable, Dr.L.Morone "High Rewards for Wind Farms Discarding Electricity 5-6th April 2011", Renewable Energy Foundation.

[15] J.Constable, L. Moroney, "Information Note: Scottish Wind Power Constraint Payments update" Renewable Energy Foundaiton.

[16] J.K Kaldellis etall, "Techno-economic comparison of energy storage systems for islands autonomous electrical networks" Renewable \& sustainable energy reviews 13 (2009).

[17] J.K. Kaldellis, D. Zafirakis "Optimum energy storage techniques for the improvement of renewable energy sources-based electricity generation economic efficiency”, Energy 32, 2007.

[18] L.E. Benitez at al, "The economics of wind power with energy storage", Energy Economics 30 (2008).

[19] Mott MacDonald, "UK Electricicty Generation Costs Update", Department of Energy \& Climate Change, June 2010.

[20] N.French, L.Gabrielli, "Discounted Cash Flow: Accounting for Uncertainty”, Mallinson report RICS 1994.

[21] O.Edberg, C.Nash et All, "Energy Storage \& Management Study", AEA technologies, September 2010.

[22] P.Denholm, G.L.Kilcinski, "Life cycle energy requirements and greenhouse gas emissions from large scale energy storage systems", Energy Conversion \& Management 45, (2004).

[23] R.Gazey, S.K.Salman, D.D.Aklil-D’Halluin, “A field application experience of integrating hydrogen technology with wind power in a remote island location, Elsevier Power Sources Journal", POWER-D-05-01096, February 2006.

[24] T.Wallner, H.Lohse-Busch, N.Shidore, "Operating strategy for a hydrogen engine for improved drive-cycle efficiency and emissions behaviour", International Journal of Hydrogen Energy, September 2008.

[25] Dr. Timothy E. Lipman, Mr. Ryan Ramos, Professor Daniel M. Kammen, "An assessment of battery and hydrogen energy storage systems integrated with wind energy resources in California" University of California, Berkeley, September 2005.

[26] U.S. Energy Information Administration Office of Integrated Analysis and Forecasting, "International Energy Outlook 2010”, DOE/EIA-0484(2010), July 2010. 